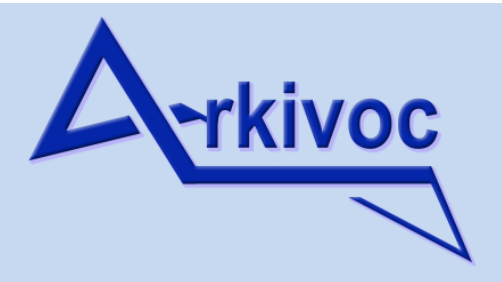

Archive for

Organic Chemistry
The Free Internet Journal

for Organic Chemistry
Account

Arkivoc 2017, part i, 99-116

\title{
Oxidative cyclizations of oximes using hypervalent iodine reagents
}

\author{
Akira Yoshimura, ${ }^{* a}$ and Viktor V. Zhdankin*b \\ a Department of Chemistry, Southern Methodist University, \\ Dallas, Texas 75275, USA \\ ${ }^{b}$ Department of Chemistry and Biochemistry, University of Minnesota Duluth, \\ Duluth, Minnesota 55812, USA \\ Email: ayoshimura@smu.edu, vzhdanki@d.umn.edu
}

\section{Abstract}

This account overviews oxidative cyclization reactions of aldoximes or ketoximes promoted by hypervalent iodine reagents. The oxidation of aldoximes by iodine(III) compounds generates nitrile oxides which can further react with appropriate substrates via intermolecular or intramolecular 1,3-dipolar cycloaddition reactions leading to a variety of nitrogen and oxygen heterocycles. Hypervalent iodine reagents can also react with ketoximes producing the corresponding heterocyclic products via intramolecular cyclization reactions. Recently, the oxidative cyclization reactions of aldoximes have been realized under catalytic conditions mediated by hypervalent iodine active species.

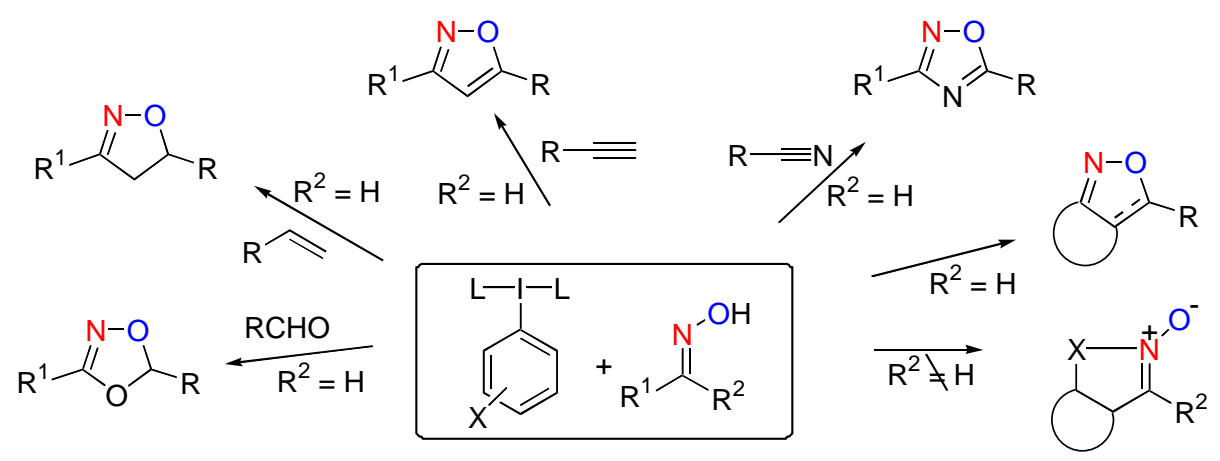

Keywords: Hypervalent iodine, 1,3-dipolar cycloaddition, heterocyclization, iodine catalysis 


\section{Table of Contents}

1. Introduction

2. Reactions of Aldoximes using Hypervalent lodine Reagents

2.1. Cycloaddition of aldoximes leading to isoxazolines

2.2. Cycloaddition of aldoximes leading to isoxazoles

2.3. Cycloaddition of aldoximes leading to other heterocycles

3. Reactions of Ketoximes using Hypervalent lodine Reagents

4. Oxidative Cyclization of Aldoximes using Catalytic Hypervalent lodine Species

5. Conclusions

6. Acknowledgements

References

\section{Introduction}

Hypervalent iodine compounds are versatile and environmentally friendly reagents that are widely used in various oxidative transformations. ${ }^{1-11}$ Oxidative cyclization of oximes using hypervalent iodine reagents can provide an efficient synthetic approach to many five-membered heterocyclic systems. ${ }^{12-16}$ Aldoximes and ketoximes are convenient and readily available starting materials for construction of various heterocyclic compounds with nitrogen and oxygen in the ring, which are commonly found in medicinal drugs, bioactive compounds, and natural products. ${ }^{17-26}$

The oxidation of aldoximes $\mathbf{1}$ using hypervalent iodine(III) reagents $\mathbf{2}$ produces nitrile oxides $\mathbf{3}$, which can react in situ with appropriate dipolarophiles such as alkenes 4, alkynes 5, nitriles 6, or aldehydes 7 via the intermolecular 1,3-dipolar cycloaddition to give the corresponding heterocyclic products such as isoxazolines $\mathbf{8}$, isoxazoles $\mathbf{9}$, oxadiazoles $\mathbf{1 0}$, or dioxazoles $\mathbf{1 1}$ (Scheme 1). ${ }^{13,27}$

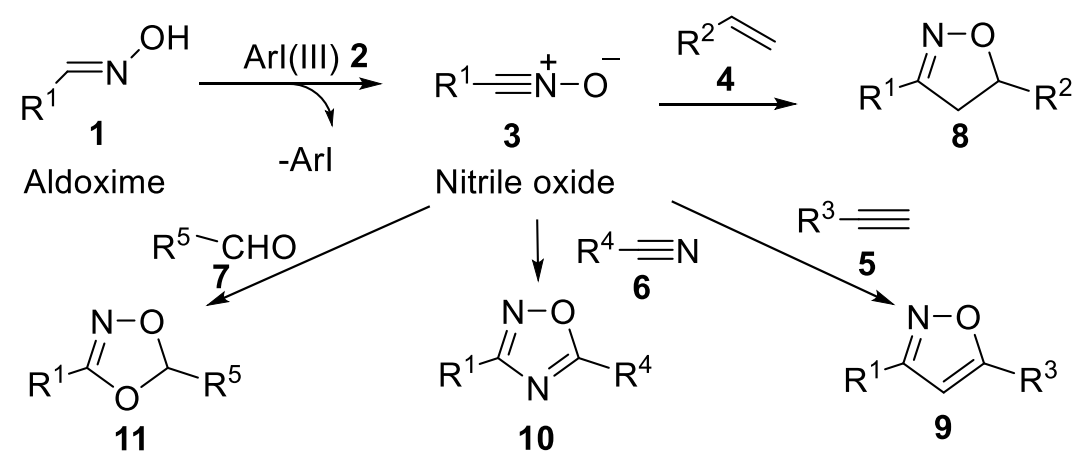

Scheme 1. Intermolecular oxidative cyclization of aldoximes 1 using hypervalent iodine(III) reagents 2.

The analogous intramolecular cyclization of the appropriate precursors $\mathbf{1 2}$ with double or triple bonds in the molecule affords the fused heterocyclic ring system 14 (Scheme 2). ${ }^{12-14,28}$ 


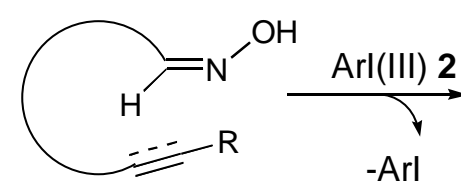

12

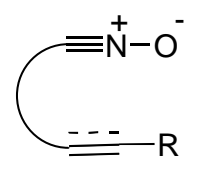

13

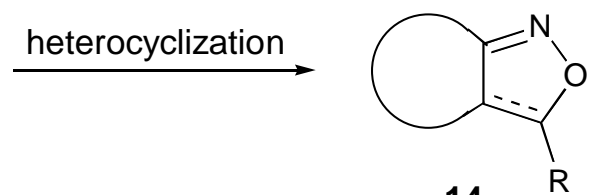

14

Scheme 2. Intramolecular oxidative cyclization of aldoximes 12 using hypervalent iodine(III) reagents 2.

Intramolecular heterocyclization reactions of ketoximes using hypervalent iodine(III) reagents have been reported by several research groups. ${ }^{29-31}$ The oxidation of ketoximes initially generates oxonitrenium ions as active intermediate species, intramolecular cyclization of which forms the corresponding heterocycles (see Section 3).

Recently, the first catalytic procedures for the preparation of isoxazolines $\mathbf{8}$, isoxazoles $\mathbf{9}$, or oxadiazoles 10 have been developed. These procedures utilize catalytic hypervalent iodine species $\mathbf{1 5}$ generated in situ from iodoarenes 16 and appropriate terminal oxidants such as $m$-CPBA or Oxone (Scheme 3). ${ }^{32,33}$ The reaction mechanism of the catalytic synthesis of oxadiazoles $\mathbf{1 0}$ has been investigated by NMR spectroscopy and ESImass spectrometry (Section 4)..$^{34}$

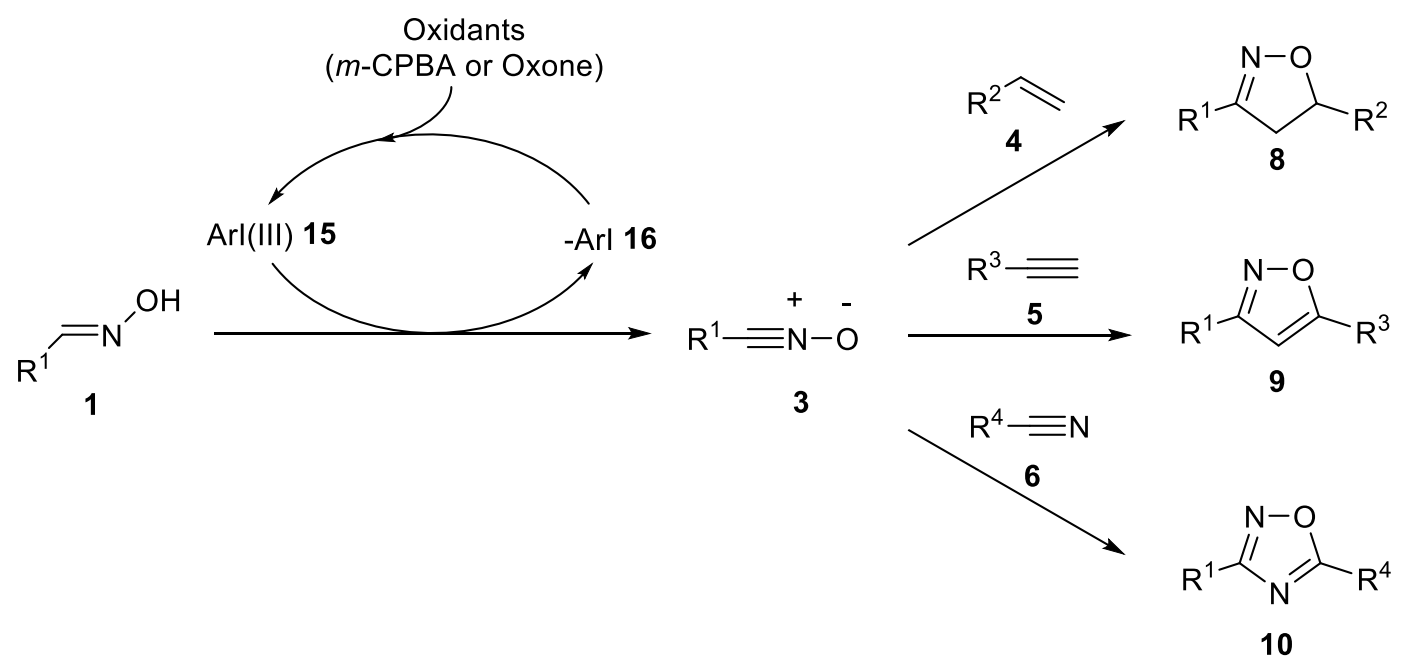

Scheme 3. Catalytic cyclization of aldoximes 1 using in situ generated hypervalent iodine(III) species 15.

In the present account, the oxidative heterocyclization reactions of aldoximes or ketoximes using various organohypervalent iodine(III) reagents are overviewed, and recent developments in hypervalent iodine catalyzed cyclizations are summarized.

\section{Reactions of aldoximes using hypervalent iodine reagents}

Various aldoximes can be converted into the highly reactive, non-isolable nitrile oxides 3 (Scheme 1) by oxidation with organohypervalent iodine(III) reagents under mild conditions. In the absence of dipolarophiles, nitrile oxides decompose at room temperature producing various products such as oxadiazole $N$-oxides, isoxazole $\mathrm{N}$-oxides, dioxadiazines, or isocyanates depending on reaction conditions. ${ }^{26,35-37}$ When hypervalent iodine(III) reagents are used for oxidation of aldoximes, the generated nitrile oxides dimerize at room 
temperature to give the corresponding oxadiazole $\mathrm{N}$-oxides. ${ }^{38,39}$ At higher temperatures, nitrile oxides can add water forming $N$-hydroxyamides as final products. For example, the reaction of aldoximes 17 with [hydroxy(tosyloxy)iodo]benzene (HTIB or Koser's reagent) at $60^{\circ} \mathrm{C}$ yields $N$-hydroxyamides 19 via intermediate formation of the corresponding nitrile oxides. A similar reaction of aldoximes $\mathbf{1 7}$ with (diacetoxyiodo)benzene (DIB) gives the corresponding $N$-acetoxyamides 18 in good yields (Scheme 4). ${ }^{40,41}$

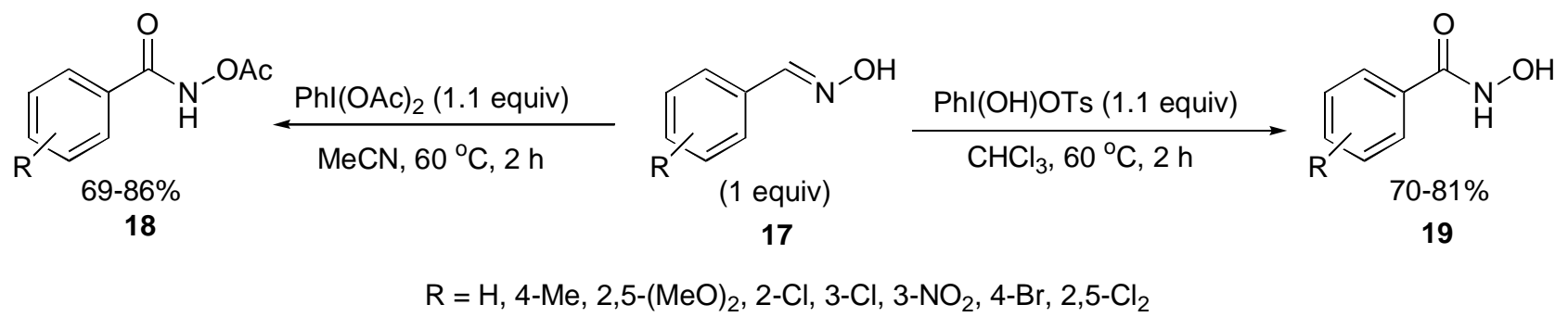

Scheme 4. Formation of $N$-hydroxy- or $N$-acetoxy-amides in the reactions of aldoximes with HTIB or DIB.

\subsection{Cycloaddition of aldoximes leading to isoxazolines}

Generation of nitrile oxides 3 in the presence of alkenes results in instantaneous 1,3-dipolar cycloaddition leading to isoxazolines. Various practically important isoxazolines have been prepared by the reaction of aldoximes and alkenes using hypervalent iodine(III) reagents, such as iodosylbenzene (PhIO), ${ }^{27}$ (diacetoxyiodo)benzene, ${ }^{42,43}$ or (dichloroiodo)benzene. ${ }^{39}$ For example, Das and co-workers reported the reaction of substituted benzaldoximes with DIB and alkenes to give the corresponding isoxazolines in good yields. ${ }^{42}$ This procedure also works for the reaction of aldoximes $\mathbf{2 0}$ with Baylis-Hillman adducts $\mathbf{2 1}$ producing the corresponding functionalized isoxazoline products 22 in good yields (Scheme 5).

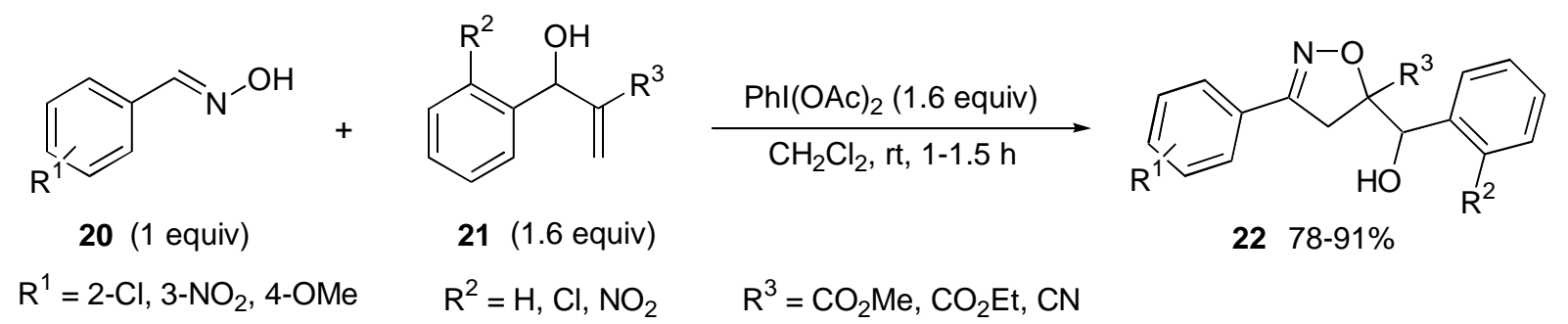

Scheme 5. Reaction of aldoximes with Baylis-Hillman adducts using DIB.

This procedure is applicable to the heterocyclization reactions of aldoximes bearing sensitive substituents such as pyrazolyl aldoximes, ${ }^{44}$ pinacol boronic acid ester benzaldoximes, ${ }^{45}$ or (6-piperidin-1-yl-9H-purin-9yl)acetaldehyde oxime. ${ }^{46}$ The reaction of aldoxime $\mathbf{2 3}$ derived from a nucleobase with alkenes 24 using [bis(trifluoroacetoxy)iodo]benzene (BTI) affords the corresponding isoxazoline products 25 in excellent yields (Scheme 6). ${ }^{46}$ Compounds $\mathbf{2 5}$ are potentially important lipid peroxide inhibitors. 


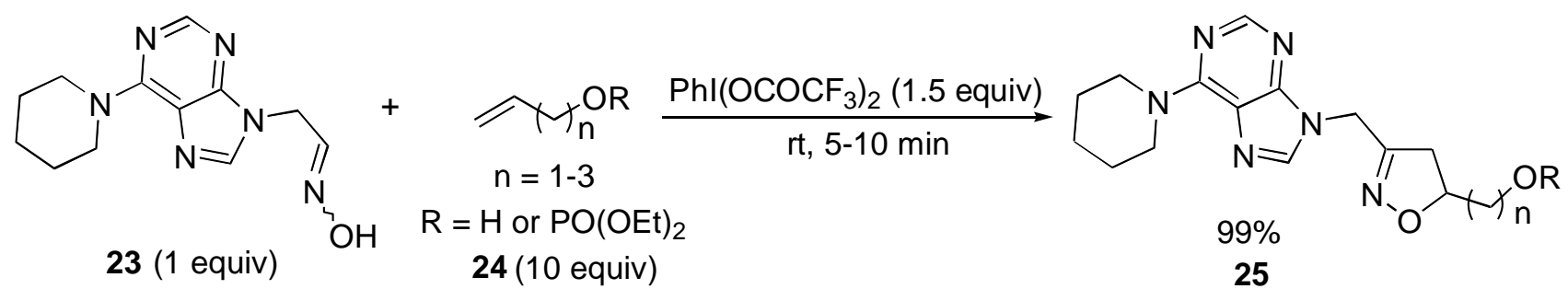

Scheme 6. Synthesis of nucleobase-substituted isoxazolines.

The hypervalent iodine(III) mediated intramolecular nitrile oxide cycloaddition (INOC) represents a convenient approach to fused heterocyclic ring system. The INOC reaction of 2-allyloxybenzaldoximes and sugar-derived aldoximes using hypervalent iodine(III) reagents selectively affords the respective ring fused isoxazoline products. ${ }^{47-50}$ In particular, Yao and co-workers have demonstrated that the INOC reaction of 2-allyloxybenzaldoximes 26 using Koser's reagent in water gives the corresponding tricyclic isoxazoline derivatives 27 in moderate to good yields (Scheme 7). ${ }^{49}$ This is an environmentally friendly reaction, which can be easily handled in water without special care. Tricyclic compounds $\mathbf{2 7}$ are potentially important pharmaceutical products.

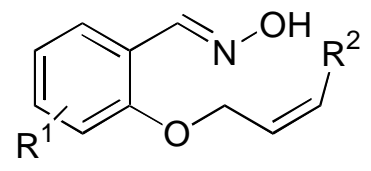

(1 equiv)

26

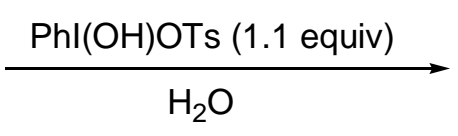

$\mathrm{H}_{2} \mathrm{O}$

(1) $\mathrm{R}^{1}=\mathrm{H}, 3,5-t-\mathrm{Bu}_{2}, 3-\mathrm{MeO}, 5-\mathrm{Cl}, 5-\mathrm{Br}, 5-\mathrm{NO}_{2}, 5-\mathrm{Br}-3-\mathrm{MeO}$ $\mathrm{R}^{2}=\mathrm{H}, \mathrm{Me}, \mathrm{Ph}, \mathrm{CH}_{2} \mathrm{OAc}$, etc.

Scheme 7. INOC reaction of 26 using Koser's reagent.

Among practically important INOC reactions, tandem oxidative inter- or intramolecular phenol dearomatization-INOC reactions have been developed. In these tandem reactions, the iodine(III) reagent serves as the oxidant for both phenol and aldoxime. ${ }^{13,16,28,51,52}$ Ciufolini and co-workers reported a practical approach to the tandem oxidative dearomatization-INOC reaction using (diacetoxyiodo)benzene (Scheme 8). ${ }^{51}$ In this procedure, the iodine(III) reagent is employed as the oxidant for the oxidative dearomatization reaction of phenolic compounds $\mathbf{2 8}$ to give the corresponding cyclohexadienone nitrile oxides $\mathbf{2 9}$, and then the intramolecular 1,3-dipolar reaction of $\mathbf{2 9}$ occurs to give the tricyclic products $\mathbf{3 0}$ in moderate to good yields. Another tandem oxidative intramolecular dearomatization-INOC reaction leading to the core skeleton of coristatins has been reported by Sorensen and co-workers. ${ }^{52}$ 
<smiles>[R]C(/C=N/O)Cc1ccc(O)cc1</smiles>

(1 equiv)

28

$\mathrm{R}=\mathrm{H}, \mathrm{NTsBn}$
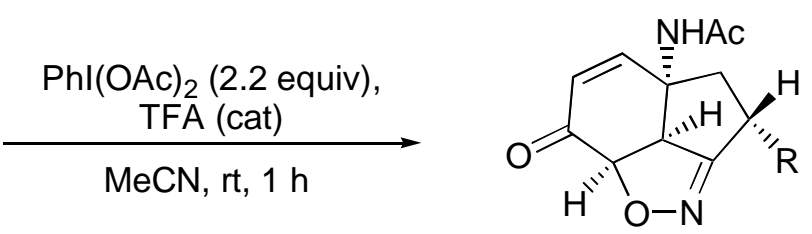

$44-71 \%$

30

Scheme 8. Tandem oxidative dearomatization of phenol-INOC reaction using DIB.

Das and co-workers have reported a simplified one-pot procedure for the synthesis of isoxazolines $\mathbf{3 3}$ from corresponding aldehydes $\mathbf{3 1}$ with hydroxylamine and alkenes $\mathbf{3 2}$ using iodosylbenzene in water in the presence of sodium dodecyl sulfate (SDS) as anionic surfactant (Scheme 9). ${ }^{53}$ This procedure has been performed with various functionalized aldehydes and alkenes, and it also can be used for the intramolecular heterocyclization of 2-allyloxybenzaldehyde.

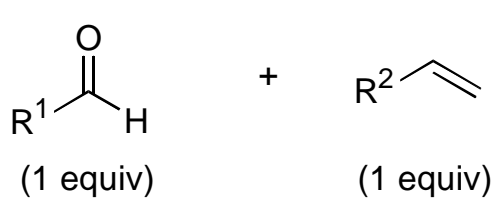

31

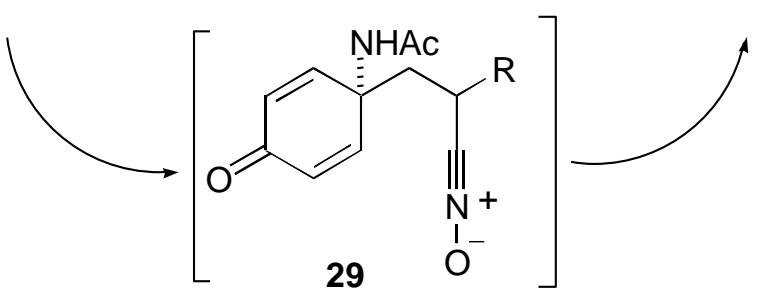

30

$$
\mathrm{R}^{1}=\mathrm{Ph}, 3-\mathrm{NO}_{2} \mathrm{C}_{6} \mathrm{H}_{4}, 4-\mathrm{MeOC}_{6} \mathrm{H}_{4}, i-\mathrm{Pr} \text {, etc.; } \mathrm{R}^{2}=\mathrm{CO}_{2} \mathrm{Et}, \mathrm{Ph} \text {, etc. }
$$

Scheme 9. One-pot synthesis of isoxazolines from aldehydes and alkenes.

\subsection{Cycloaddition of aldoximes leading to isoxazoles}

Several synthetic procedures for the preparation of isoxazoles via cycloaddition of nitrile oxides and alkynes have recently been developed. ${ }^{17-19}$ In particular, the reaction of various aldoximes with alkynes in the presence of organohypervalent iodine(III) reagents such as DIB, ${ }^{48,51,54-57} \mathrm{BTI},{ }^{46,58,59}$ Koser's reagent, $^{49,60}$ or PhIO, ${ }^{27,61}$ leads to oxidative heterocyclization yielding the corresponding isoxazoles. This procedure is applicable to various internal or terminal alkynes under mild condition. For example, the reaction of aromatic or aliphatic aldoximes with various alkynes using BTI affords the corresponding isoxazole products in good yields. ${ }^{58}$ The BTI induced heterocyclization has been used for the efficient synthesis of nucleoside-substituted isoxazoles $\mathbf{3 6}$ from aldoximes $\mathbf{3 4}$ and nucleoside $\mathbf{3 5}$ (Scheme 10). 


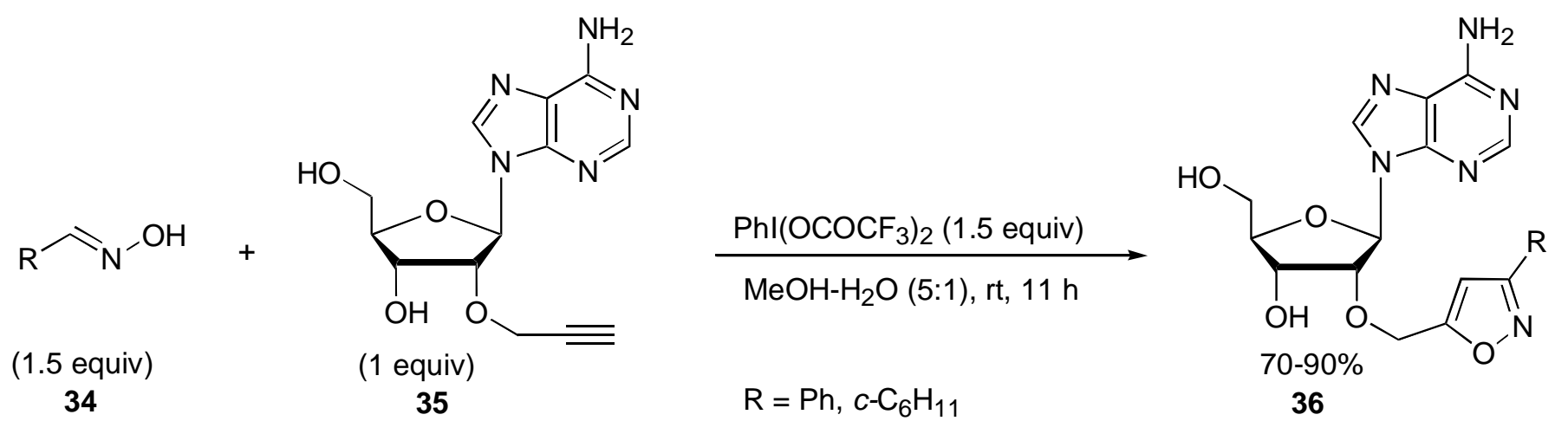

Scheme 10. Oxidative cycloaddition of aldoximes with alkyne-substituted nucleoside.

Several oxidative cycloaddition reactions of internal alkynes with aldoximes using iodine(III) reagents have been reported. ${ }^{46,54,60}$ The reactions of strained cyclic alkynes such as cyclooctyne derivatives with nitrile oxides generated from aldoximes and iodine(III) reagents are especially important in bioorthogonal chemistry. ${ }^{55-58}$ For example, the reaction of lactose oxime with dibenzocyclooctyne derivatives using DIB gives the corresponding isoxazoles in good yields. ${ }^{56}$ The obtained compound can be modified with the biotin tag, and can then be useful for an immobilization reaction to the surface of Streptavidin. Boons and co-workers reported the preparation of amphiphilic polymeric compounds $\mathbf{3 9}$ by using strain-promoted heterocyclization of polymer-supported aldoxime $\mathbf{3 7}$ and cyclooctyne derivatives 38 using DIB (Scheme 11). ${ }^{57}$ The polymers produced can form stable molecular assemblies in aqueous solution because of their hydrophilic-hydrophobic balance. These self-assembled products can further form nanoparticles potentially useful in materials or biomaterials sciences.
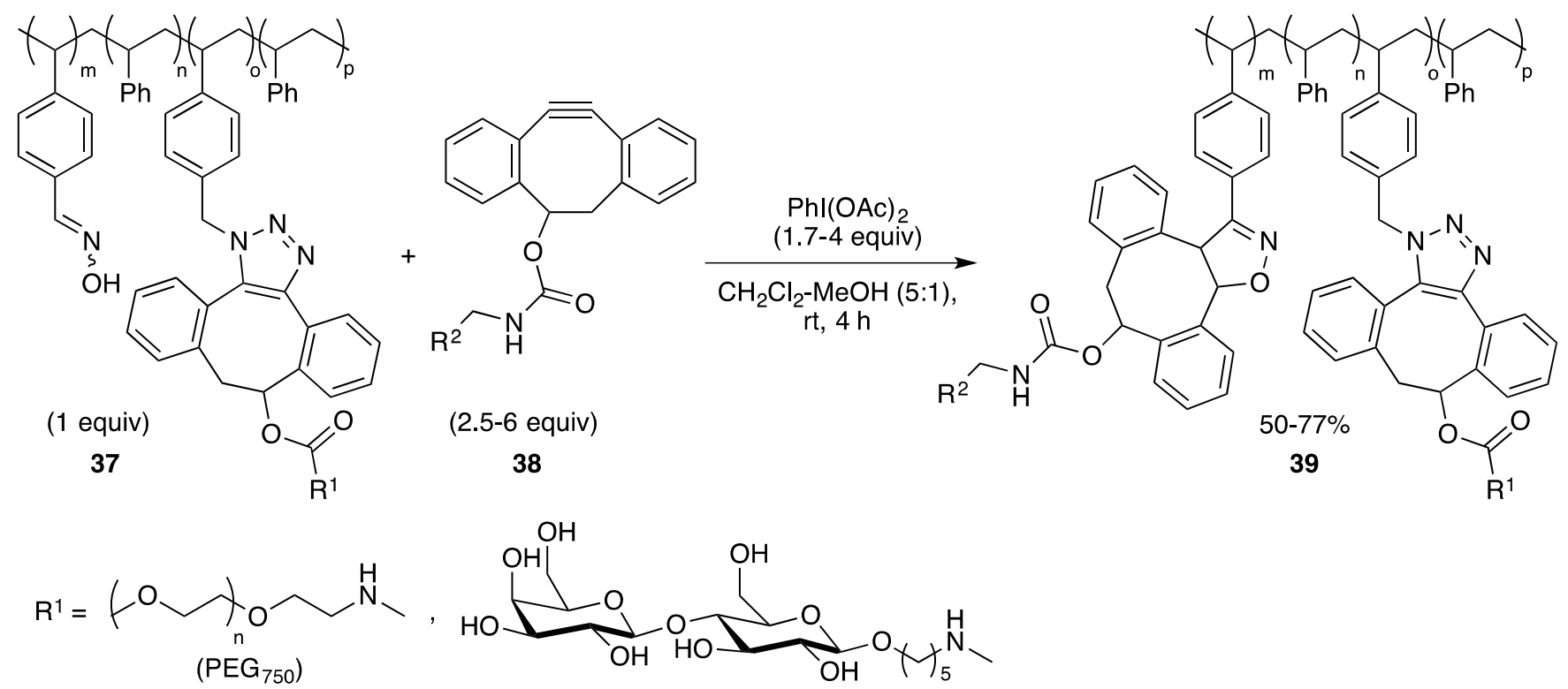<smiles></smiles>

Scheme 11. DIB mediated preparation of amphiphilic polymers. 
The iodine(III)-mediated intramolecular cyclizations of aldoximes can be performed under conditions similar to the intermolecular reactions conditions. ${ }^{49,53}$ The intramolecular cyclization reaction of 2propargyloxybenzaldoximes using Koser's reagent in water gives the corresponding tricyclic isoxazole derivatives in good yields. Das and co-workers have also reported an efficient one-pot procedure for the preparation of tricyclic isoxazole product $\mathbf{4 1}$ from 2-propargyloxybenzaldehyde $\mathbf{4 0}$ and hydroxylamine using iodosylbenzene in the presence of anionic surfactant (Scheme 12). ${ }^{53}$
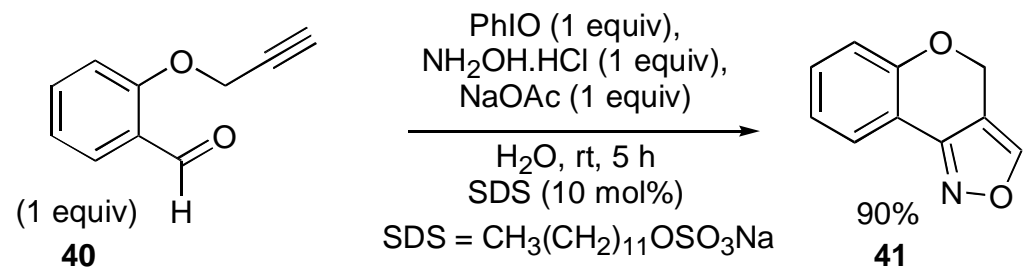

Scheme 12. One-pot synthesis procedure of isoxazole from 2-propargyloxybenzaldehyde.

Alkynyliodonium salts are electron-deficient alkyne derivatives useful for heterocyclization reactions. 8,62,63 In a specific example, Stang and Murch reported the reaction of alkynyliodonium salt $\mathbf{4 3}$ with nitrile oxide generated from aldoxime $\mathbf{4 2}$ using iodosylbenzene to give the corresponding isoxazoles $\mathbf{4 5}$ in moderate yields. ${ }^{61}$ This reaction probably involved the intermediate iodonium salt $\mathbf{4 4}$, formed in situ from aldoxime $\mathbf{4 2}$ and alkynyliodonium salts $\mathbf{4 3}$, followed by loss of the of a phenyliodonium moiety to give the isoxazole products 45 (Scheme 13).

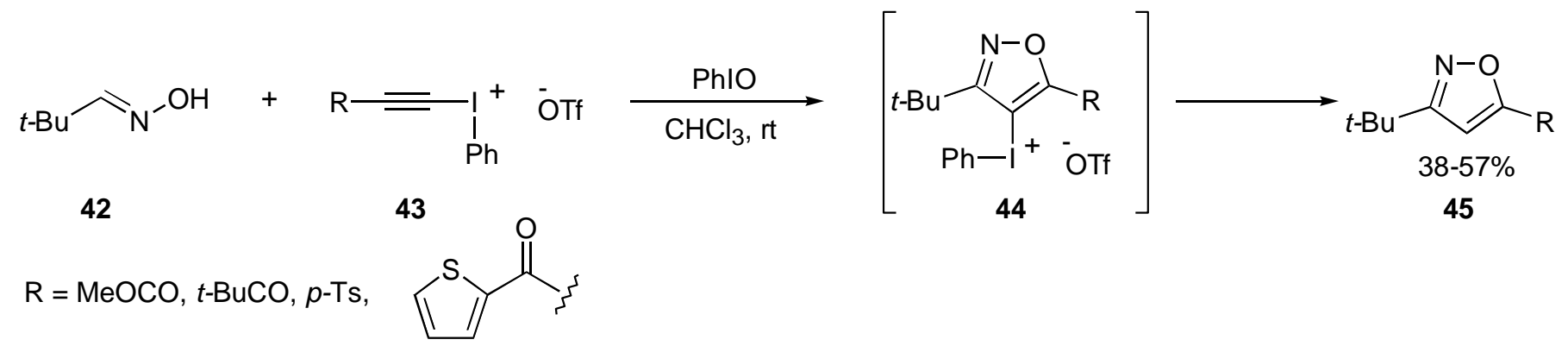

Scheme 13. Cycloaddition of alkynyliodonum salts with an aldoxime using PhIO.

\subsection{Cycloaddition of aldoximes leading to other heterocycles}

Oxidative heterocyclization reactions of aldoximes with nitriles or aldehydes using hypervalent iodine(III) reagents have also been reported. ${ }^{27,34,64}$ For example, treatment of aliphatic or aromatic aldoximes $\mathbf{4 6}$ with 2[hydroxy(trifluoromethanesufonyloxy)]iodobenzoic acid $\mathbf{4 7}$ in acetonitrile solution affords the corresponding oxadiazoles 48 in moderate to good yields (Scheme 14). ${ }^{34}$ This reaction also proceeds smoothly in solutions of other nitriles under similar conditions affording 1,2,4-oxadiazoles 48 in moderate to good yields. 


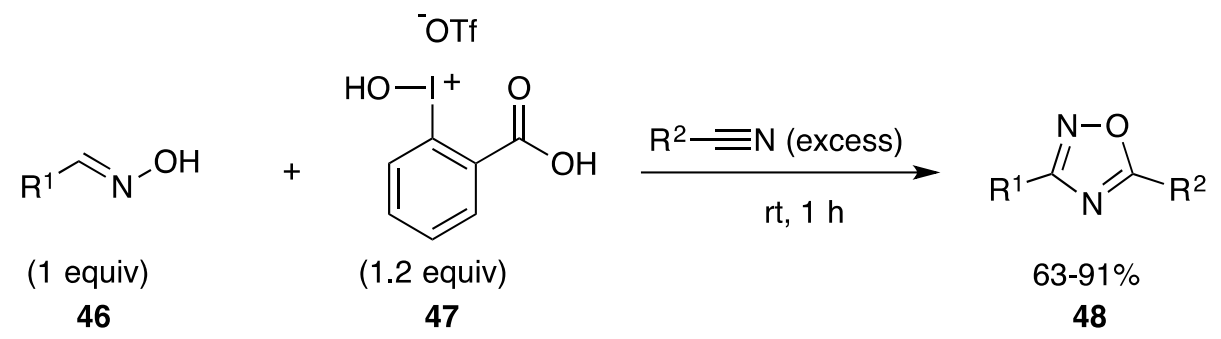

Scheme 14. Cycloaddition of aldoximes with nitriles using PhIO.

Oxidative cycloaddition reactions of aldoximes with aldehydes using an iodine(III) reagent have been reported by Tanaka and co-workers. ${ }^{27}$ For example, the reaction of benzaldoxime $\mathbf{4 9}$ with benzaldehyde $\mathbf{5 0}$ using iodosylbenzene as the oxidant affords 3,5-diphenyl-1,2,4-dioxazole 51 in low yield (Scheme 15).

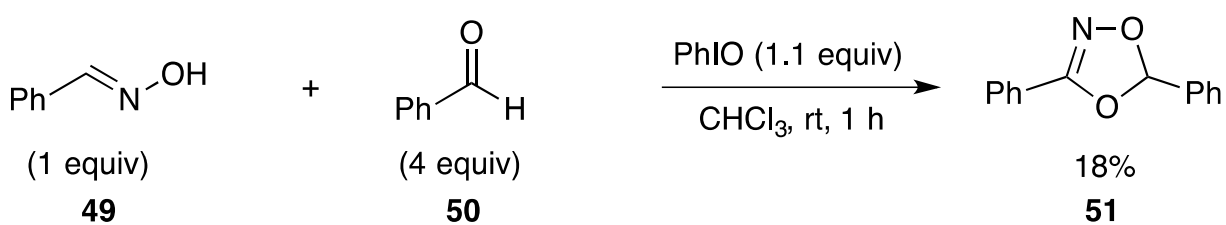

Scheme 15. Oxidative cycloaddition of benzaldoxime to benzaldehyde.

\section{Reactions of ketoximes using hypervalent iodine reagents}

Syntheses of various heterocyclic compounds using ketoximes as building blocks have been reported. ${ }^{65,66}$ Organohypervalent iodine(III) compounds are particularly effective reagents for the oxidation of ketoximes. Reaction of ketoximes $\mathbf{5 2}$ with iodine(III) reagents probably involves the initial formation of oxonitrenium species $\mathbf{5 3}$ followed by intramolecular cyclization to form heterocyclic products $\mathbf{5 4}$ (Scheme 16).

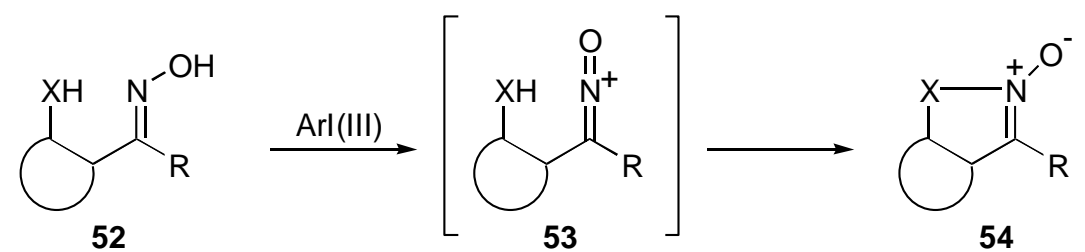

Scheme 16. Intramolecular cyclization of ketoximes using hypervalent iodine(III) reagents.

Reactions of ketoximes with iodine(III) reagents in the presence of water can lead to oxidative cleavage producing the corresponding ketones. ${ }^{67-71}$ Zefirov and co-workers reported an efficient conversion of oximes into the acetoxy nitroso compounds..$^{72}$ This reaction involves initial generation of oxonitrenium intermediates from oximes using 4-bromo(diacetoxyiodo)benzene followed by their reaction with $\mathrm{AcO}^{-}$affording acetoxy nitroso compounds in good yields.

The cyclization reactions of oximes using hypervalent iodine(III) reagents can proceed with various nucleophiles, such as alkenes, ${ }^{73-76}$ alcohols, ${ }^{77-81}$ or amines, ${ }^{67,82}$ within the molecule to produce the respective cyclic compounds. For example, Aggarwal and co-workers have reported an efficient synthesis of 2,3- 
diphenylquinoxaline-1-oxides 56 from benzyl- $\alpha$-arylimino oximes 55 using DIB (Scheme 17). ${ }^{76}$ Products 56 are potentially important as angiotensin II receptor antagonists.<smiles>[R]c1cc(N=C(C(=NO)c2ccccc2)c2ccccc2)cc([R])c1[R]</smiles>

(1 equiv)
55

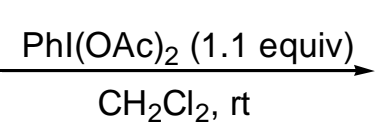

$$
\mathrm{CH}_{2} \mathrm{Cl}_{2} \text {, rt }
$$$$
\text { ( }
$$

$\mathrm{R}^{1}=\mathrm{H}, \mathrm{Me}, \mathrm{Cl} ; \quad \mathrm{R}^{2}=\mathrm{H}, \mathrm{F}, \mathrm{Cl}, \mathrm{Br}, \mathrm{Me}, \mathrm{OMe}$<smiles>[R]c1cc2nc(-c3ccccc3)c(-c3ccccc3)[n+]([O-])c2c([R])c1[R]</smiles>

$60-75 \%$

56

Scheme 17. Preparation of 2,3-diphenylquinoxaline-1-oxides $\mathbf{5 6}$ from benzyl- $\alpha$-arylimino oximes $\mathbf{5 5 .}$

Reactions of ketoximes in which an $\mathrm{N}-\mathrm{O}$ bond is formed, giving isoxazole $\mathrm{N}$-oxide derivatives, have been reported. ${ }^{77-80}$ Effective procedures for the preparation of various isoxazole $N$-oxides from ketoximes have been developed by several research groups. Yao and co-workers have reported the Koser's reagent-induced oxidative heterocyclization reactions of ketoximes in water or methanol producing the corresponding isoxazole $\mathrm{N}$-oxides in good yields. ${ }^{77}$ The reaction of bisoxime $\mathbf{5 7}$ with Koser's reagent in water affords benzodiisoxazole di-N-oxide 58 as the sole product in good yield (Scheme 18). The analogous iodine(III)mediated reactions of ketoximes with amines as nucleophiles result in $\mathrm{N}-\mathrm{N}$ bond formation producing the corresponding pyrazolin-5-one $\mathrm{N}$-oxide derivatives. ${ }^{67,82}$<smiles>C/C(=N\O)c1cc(/C(C)=N/O)c(O)cc1O</smiles>

57

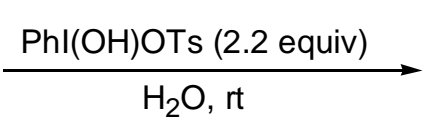

$\mathrm{H}_{2} \mathrm{O}, \mathrm{rt}$

(n)<smiles>Cc1c2cc3c([N+]([O-])[O-])o[n+]([O-])c3cc2o[n+]1[O-]</smiles>

58

Scheme 18. Reaction of bisoxime 57 with Koser's reagent in water.

Ciufolini and co-workers have reported the hypervalent iodine(III)-induced oxidation of $\alpha$-oxo-oximes to nitrile oxides. ${ }^{83}$ The oxidation of $\alpha$-oxo-ketoximes 59 with DIB in the presence of norbornene 60 in methanol gave the corresponding isoxazoline compounds 61 in moderate yields. The mechanism of this reaction starts from the generation of iodine(III) species 62 via ligand exchange followed by a methanol-promoted solvolytic fragmentation of 63 to form nitrile oxide 64 . Finally, the nitrile oxide 64 reacts with norbornene 60 to give the final isoxazoline products 61 (Scheme 19). 
<smiles>O=C1CCCCCC1=NO</smiles><smiles>[Mg][TeH]</smiles>

59<smiles>COC(=O)C1=NOCCCC1</smiles>

62

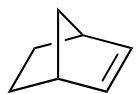

(1.2 equiv)

60

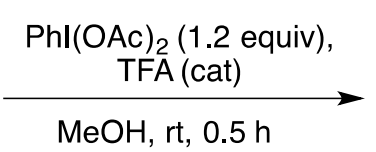

MeOH, rt, $0.5 \mathrm{~h}$

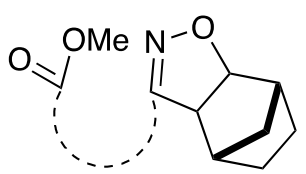

$56-72 \%$

61

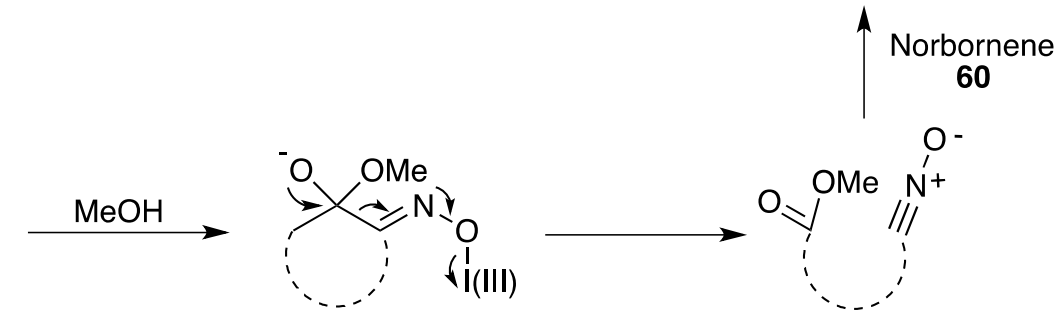

63

64

Scheme 19. Oxidation of $\alpha$-oxo-oximes to nitrile oxide using DIB.

\section{Oxidative cyclization of aldoximes using catalytic hypervalent iodine species}

Catalytic reactions involving hypervalent iodine active species is a very dynamic area of current research. ${ }^{3,6,84-86}$ Recently the first examples of iodine(III) catalyzed oxidative cycloaddition reactions of aldoximes have been reported. ${ }^{32-34,64,87,88}$ In 2013, our group was the first to report the hypervalent iodineinduced catalytic cyclization of aldoximes. ${ }^{32}$ We have found that oxidative heterocyclization of various aldoximes 65 with alkenes 66 or alkynes 67 in the presence of catalytic aryl iodide and Oxone as the oxidant affords the corresponding isoxazolines 68 or isoxazoles 69 in moderate to good yields (Scheme 20). Later, Yan and co-workers reported a similar catalytic iodine(III)-mediated oxidative cycloaddition of aldoximes with alkenes or alkynes. ${ }^{87,88}$

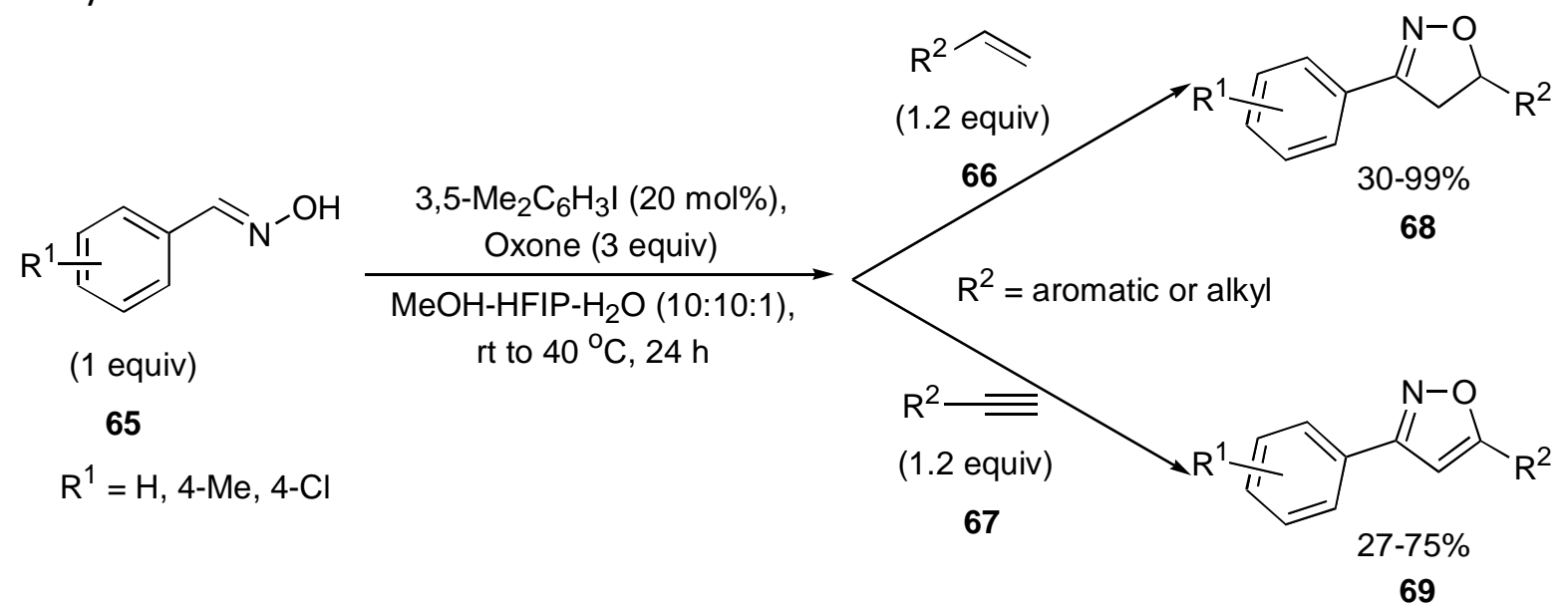

Scheme 20. Catalytic heterocyclization of aldoximes with alkenes or alkynes.

Recently, we have reported the catalytic oxidative cyclization of aldoximes $\mathbf{7 0}$ with maleimides $\mathbf{7 1}$ using highly active hypervalent iodine(III) species producing the corresponding pyrrolo-isoxazoles $\mathbf{7 2}$ in moderate to good yields (Scheme 21). ${ }^{33}$ This catalytic reaction probably involves the highly reactive hydroxy(aryl)iodonium species generated from 2-iodobenzoic acid and $m$-chloroperoxybenzoic acid ( $m$-CPBA) in the presence of trifluoromethanesulfonic acid. The presence of these active iodine(III) species in the reaction mixture was confirmed by ${ }^{1} \mathrm{H}$ NMR spectrocopy and ESI-mass spectrometry. 


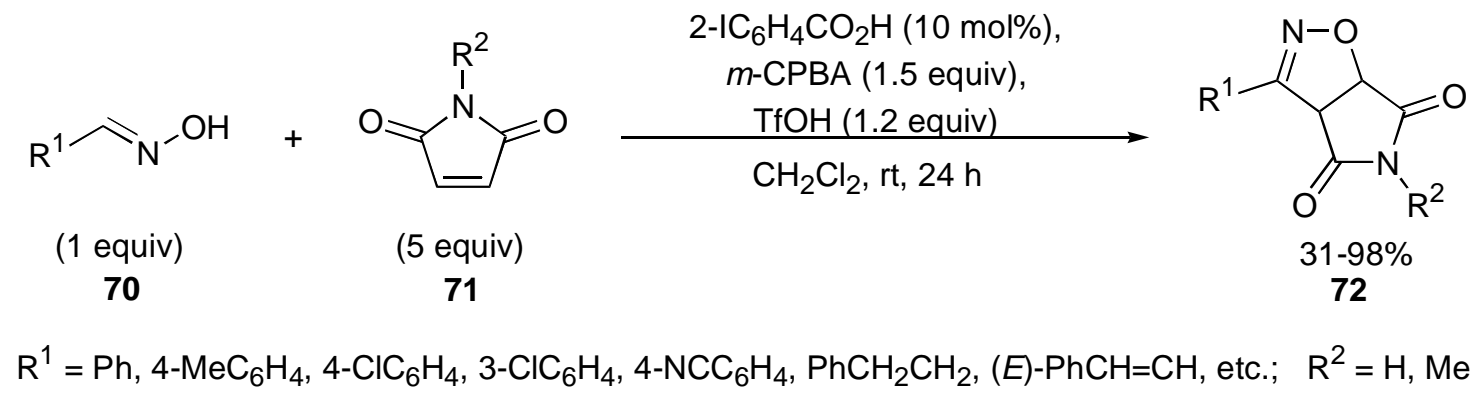

Scheme 21. Oxidative cyclization of aldoximes with maleimides by catalytic hypervalent iodine species.

Recently, the catalytic hypervalent iodine-mediated oxidative cyclization reactions of aldoximes with nitriles have been reported. ${ }^{34,64}$ This process also involves the hydroxy(aryl)iodonium species generated in situ from 2-iodobenzoic acid, $m$-CPBA and trifluoromethanesulfonic acid as confirmed by ${ }^{1} \mathrm{H}$ NMR spectroscopy and ESI-mass spectrometry. The catalytic oxidative cyclization reaction of aldoximes $\mathbf{7 3}$ and nitriles 74 affords various 1,2,4-oxadiazole products 75 (Scheme 22).

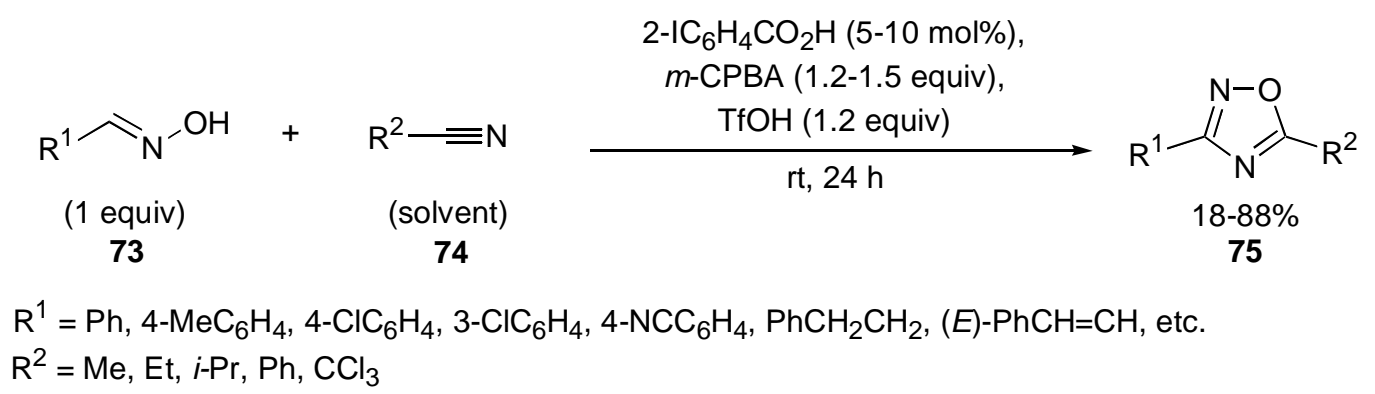

Scheme 22. Preparation of oxadiazoles from aldoximes with nitriles using catalytic hypervalent iodine species.

\section{Conclusions}

This account demonstrates the active current interest and high research activity in oxidative heterocyclization reactions promoted by the environmentally sustainable organohypervalent iodine reagents. Oxidative cycloaddition reactions of aldoximes or ketoximes with appropriate dipolarophiles in the presence of common iodine(III) oxidants provide an efficient synthetic approach to various nitrogen and oxygen heterocycles. The oxidation of aldoximes generates nitrile oxides, which are efficient 1,3-dipolar reactants in intra- or intermolecular cycloadditions. Suitably functionalized ketoximes and hypervalent iodine(III) reagents have been utilized as efficient reactants in intramolecular heterocyclization reactions. Moreover, catalytic methodologies for aldoxime heterocyclization using various iodoarenes as precatalysts have been recently developed. We expect that this synthetically important area of hypervalent iodine chemistry will continue to attract significant research activity in the future.

\section{Acknowledgements}

This work was supported by a research grant from the NSF (CHE-1262479). 


\section{References}

1 Wirth, T.; ed. Top. Curr. Chem. 2016, 373.

2 Zhdankin, V. V. In Hypervalent lodine Chemistry: Preparation, Structure and Synthetic Application of Polyvalent lodine Compounds; John Wiley \& Sons Ltd., 2014.

3 Yoshimura, A.; Zhdankin, V. V. Chem. Rev. 2016, 116, 3328-3435.

https://doi.org/10.1021/acs.chemrev.5b00547

4 Dohi, T.; Kita, Y. Curr. Org. Chem. 2016, 20, 580-615.

https://doi.org/10.2174/1385272819666150716173142

5 Kohlhepp, S. V.; Gulder, T. Chem. Soc. Rev. 2016, 45, 6270-6288.

https://doi.org/10.1039/C6CS00361C

6 Narayan, R.; Manna, S.; Antonchick, A. P. Synlett 2015, 26, 1785-1803.

https://doi.org/10.1055/s-0034-1379912

7 Li, Y.; Hari, D. P.; Vita, M. V.; Waser, J. Angew. Chem. Int. Ed. 2016, 55, 4436-4454.

https://doi.org/10.1002/anie.201509073

8 Waser, J. Synlett 2016, 27, 2761-2773.

https://doi.org/10.1055/s-0036-1589409

9 Olofsson, B.; Merritt, E. Synthesis 2011, 517-538.

https://doi.org/10.1055/s-0030-1258328

10 Romero, R. M.; Woeste, T. H.; Muniz, K. Chem. Asian J. 2014, 9, 972-983.

https://doi.org/10.1002/asia.201301637

11 Zheng, Z.; Zhang-Negrerie, D.; Du, Y.; Zhao, K. Sci. China: Chem. 2014, 57, 189-214.

https://doi.org/10.1007/s11426-013-5043-1

12 Kotali, A.; Kotali, E.; Lafazanis, I. S.; Harris, P. A. Adv. Org. Synth. 2013, 4, 267-316.

13 Turner, C. D.; Ciufolini, M. A. Arkivoc 2011, (i), 410-428.

14 Kotali, A.; Kotali, E.; Lafazanis, I. S.; Harris, P. A. Curr. Org. Synth. 2010, 7, 62-77.

https://doi.org/10.2174/157017910790820355

15 Traore, M.; Ahmed-Ali, S.; Peuchmaur, M.; Wong, Y.-S. Tetrahedron 2010, 66, 5863-5872.

https://doi.org/10.1016/j.tet.2010.04.135

16 Liang, H.; Ciufolini, M. A. Tetrahedron 2010, 66, 5884-5892.

https://doi.org/10.1016/j.tet.2010.05.020

17 Pellissier, H. Tetrahedron 2007, 63, 3235-3285.

https://doi.org/10.1016/j.tet.2007.01.009

18 Nair, V.; Suja, T. D. Tetrahedron 2007, 63, 12247-12275.

https://doi.org/10.1016/j.tet.2007.09.065

19 Hashimoto, T.; Maruoka, K. Chem. Rev. 2015, 115, 5366-5412.

https://doi.org/10.1021/cr5007182

20 Kozikowski, A. P. Acc. Chem. Res. 1984, 17, 410-416.

https://doi.org/10.1021/ar00108a001

21 Kumar, K. A.; Govindaraju, M.; Renuka, N.; Kumar, G. V. J. Chem. Pharm. Res. 2015, 7, 250-257.

22 Rane, D.; Sibi, M. Curr. Org. Synth. 2011, 8, 616-627.

https://doi.org/10.2174/157017911796957320

23 Browder, C. C. Curr. Org. Synth. 2011, 8, 628-644. 
https://doi.org/10.2174/157017911796957393

24 Jaeger, V.; Frey, W.; Bathich, Y.; Shiva, S.; Ibrahim, M.; Henneboehle, M.; LeRoy, P.-Y.; Imerhasan, M. Z. Naturforsch., B: J. Chem. Sci. 2010, 65, 821-832.

25 Burrell, A. J. M.; Coldham, I. Curr. Org. Synth. 2010, 7, 312-331.

https://doi.org/10.2174/157017910791414472

26 Feuer, H.; ed. Nitrile Oxides, Nitrones, and Nitronates in Organic Synthesis; Volume 2; John Wiley \& Sons, Inc., 2008.

27 Tanaka, S.; Ito, M.; Kishikawa, K.; Kohmoto, S.; Yamamoto, M. Nippon Kagaku Kaishi 2002, 471-473.

https://doi.org/10.1246/nikkashi.2002.471

28 Ciufolini, M. A. Can. J. Chem. 2014, 92, 186-193.

https://doi.org/10.1139/cjc-2013-0543

29 Mosher, M. D. Curr. Org. Synth. 2011, 8, 645-658.

https://doi.org/10.2174/157017911796957401

30 Zhong, C.; Gautam, L. N. S.; Petersen, J. L.; Akhmedov, N. G.; Shi, X. Chem. Eur. J. 2010, 16, 8605-8609. https://doi.org/10.1002/chem.201001237

31 Jiang, H.; Elsner, P.; Jensen, K. L.; Falcicchio, A.; Marcos, V.; Joergensen, K. A. Angew. Chem. Int. Ed. 2009, 48, 6844-6848.

https://doi.org/10.1002/anie.200901446

32 Yoshimura, A.; Middleton, K. R.; Todora, A. D.; Kastern, B. J.; Koski, S. R.; Maskaev, A. V.; Zhdankin, V. V. Org. Lett. 2013, 15, 4010-4013.

https://doi.org/10.1021/ol401815n

33 Yoshimura, A.; Nguyen, K. C.; Rohde, G. T.; Saito, A.; Yusubov, M. S.; Zhdankin, V. V. Adv. Synth. Catal. 2016, 358, 2340-2344.

https://doi.org/10.1002/adsc.201600331

34 Yoshimura, A.; Nguyen, K. C.; Klasen, S. C.; Postnikov, P. S.; Yusubov, M. S.; Saito, A.; Nemykin, V. N.; Zhdankin, V. V. Asian J. Org. Chem. 2016, 5, 1128-1133.

https://doi.org/10.1002/ajoc.201600247

35 Gucma, M.; Golebiewski, W. M. J. Heterocycl. Chem. 2014, 51, 572-578.

https://doi.org/10.1002/jhet.1792

36 Yu, Z.-X.; Caramella, P.; Houk, K. N. J. Am. Chem. Soc. 2003, 125, 15420-15425.

https://doi.org/10.1021/ja037325a

37 Curran, D. P.; Scanga, S. A.; Fenk, C. J. J. Org. Chem. 1984, 49, 3474-3478.

https://doi.org/10.1021/jo00193a008

38 Prakash, O.; Pannu, K. Arkivoc 2007, xiii, 28-33.

39 Radhakrishna, A. S.; Sivaprakash, K.; Singh, B. B. Synth. Commun. 1991, 21, 1625-1629. https://doi.org/10.1080/00397919108021062

40 Ghosh, H.; Patel, B. K. Org. Biomol. Chem. 2010, 8, 384-390. https://doi.org/10.1039/B917096K

41 Ghosh, H.; Baneerjee, A.; Rout, S. K.; Patel, B. K. Arkivoc 2011, 209-216.

42 Das, B.; Holla, H.; Mahender, G.; Banerjee, J.; Reddy, M. R. Tetrahedron Lett. 2004, 45, 7347-7350. https:// https://doi.org/10.1016/i.tetlet.2010.09.038doi.org/10.1016/j.tetlet.2004.07.159

43 Yang, H.-T.; Ruan, X.-J.; Miao, C.-B.; Sun, X.-Q. Tetrahedron Lett. 2010, 51, 6056-6059. https://doi.org/10.1016/j.tetlet.2010.09.038 
44 Kumar, R.; Kumar, M.; Prakash, O. Heteroat. Chem. 2016, 27, 228-234.

https://doi.org/10.1002/hc.21320

45 Harding, S. L.; Marcuccio, S. M.; Paul, S. G. Beilstein J. Org. Chem. 2012, 8, 606-612. https://doi.org/10.3762/bjoc.8.67

46 Balalas, T.; Peperidou, C.; Hadjipavlou-Litina, D. J.; Litinas, K. E. Synthesis 2016, 48, 281-292.

47 Das, B.; Holla, H.; Mahender, G.; Venkateswarlu, K.; Bandgar, B. P. Synthesis 2005, 1572-1574. https://doi.org/10.1055/s-2005-865314

48 Bhosale, S.; Kurhade, S.; Vyas, S.; Palle, V. P.; Bhuniya, D. Tetrahedron 2010, 66, 9582-9588. https://doi.org/10.1016/i.tet.2010.10.029

49 Raihan, M. J.; Kavala, V.; Kuo, C.-W.; Raju, B. R.; Yao, C.-F. Green Chem. 2010, 12, 1090-1096. https://doi.org/10.1039/b926085d

50 Chatterjee, N.; Pandit, P.; Halder, S.; Patra, A.; Maiti, D. K. J. Org. Chem. 2008, 73, 7775-7778. https://doi.org/10.1021/jo801337k

51 Mendelsohn, B. A.; Lee, S.; Kim, S.; Teyssier, F.; Aulakh, V. S.; Ciufolini, M. A. Org. Lett. 2009, 11, 15391542.

https://doi.org/10.1021/ol900194v

52 Frie, J. L.; Jeffrey, C. S.; Sorensen, E. J. Org. Lett. 2009, 11, 5394-5397. https://doi.org/10.1021/ol902168g

53 Pal, G.; Paul, S.; Ghosh, P. P.; Das, A. R. RSC Adv. 2014, 4, 8300-8307. https://doi.org/10.1039/c3ra46129g

54 Singhal, A.; Parumala, S. K. R.; Sharma, A.; Peddinti, R. K. Tetrahedron Lett. 2016, 57, 719-722. https://doi.org/10.1016/j.tetlet.2015.10.038

55 Wendeln, C.; Singh, I.; Rinnen, S.; Schulz, C.; Arlinghaus, H. F.; Burley, G. A.; Ravoo, B. J. Chem. Sci. 2012, 3, 2479-2484.

https://doi.org/10.1039/c2sc20555f

56 Sanders, B. C.; Friscourt, F.; Ledin, P. A.; Mbua, N. E.; Arumugam, S.; Guo, J.; Boltje, T. J.; Popik, V. V.; Boons, G.-J. J. Am. Chem. Soc. 2011, 133, 949-957.

https://doi.org/10.1021/ja1081519

57 Ledin, P. A.; Kolishetti, N.; Boons, G.-J. Macromolecules 2013, 46, 7759-7768. https://doi.org/10.1021/ma400913a

58 Jawalekar, A. M.; Reubsaet, E.; Rutjes, F. P. J. T.; van Delft, F. L. Chem. Commun. 2011, 47, 3198-3200. https://doi.org/10.1039/c0cc04646a

59 Niu, T.-f.; Lv, M.-f.; Wang, L.; Yi, W.-b.; Cai, C. Org. Biomol. Chem. 2013, 11, 1040-1048. https://doi.org/10.1039/c2ob26990b

60 Jadhav, R. D.; Mistry, H. D.; Motiwala, H.; Kadam, K. S.; Kandre, S.; Gupte, A.; Gangopadhyay, A. K.; Sharma, R. J. Heterocycl. Chem. 2013, 50, 774-780.

https://doi.org/10.1002/jhet.1556

61 Stang, P. J.; Murch, P. Tetrahedron Lett. 1997, 38, 8793-8794.

https://doi.org/10.1016/S0040-4039(97)10418-X

62 Brand, J. P.; Waser, J. Chem. Soc. Rev. 2012, 41, 4165-4179.

https://doi.org/10.1039/c2cs35034c

63 Zhdankin, V. V.; Stang, P. J. Tetrahedron 1998, 54, 10927-10966. https://doi.org/10.1016/S0040-4020(98)00410-4 
64 Yoshimura, A.; Nguyen, K. C.; Klasen, S. C.; Saito, A.; Nemykin, V. N.; Zhdankin, V. V. Chem. Commun. 2015, 51, 7835-7838.

https://doi.org/10.1039/C5CC02009C

65 Abele, E.; Abele, R. Curr. Org. Synth. 2014, 11, 403-428.

https://doi.org/10.2174/1570179410666131217234916

66 Abele, E.; Lukevics, E. Heterocycles 2000, 53, 2285-2336.

https://doi.org/10.3987/REV-00-536

67 Spyroudis, S.; Varvoglis, A. Chimika Chronika 1982, 11, 173-179.

68 Kumar, A.; Ahmad, P.; Akanksha; Murya, R. A. Comb. Chem. High Throughput Screen. 2005, 8, 445-447. https://doi.org/10.2174/1386207054546522

69 Pundeer, R.; Chaudhri, V.; Kinger, M.; Prakash, O. Indian J. Chem., Sect. B: Org. Chem. Incl. Med. Chem. 2007, 46B, 834-837.

70 Bhavani, N.; Lily, K. Oxidation Commun. 1997, 20, 87-92.

71 Moriarty, R. M.; Prakash, O.; Vavilikolanu, P. R. Synth. Commun. 1986, 16, 1247-1254. https://doi.org/10.1080/00397918608056372

72 Zhutov, E. V.; Skornyakov, Y. V.; Proskurina, M. V.; Zefirov, N. S. Russ. J. Org. Chem. 2003, 39, $1672-1673$. https://doi.org/10.1023/B:RUJO.0000013147.86594.7c

73 Ohsawa, A.; Arai, H.; Igeta, H.; Akimoto, T.; Tsuji, A.; litaka, Y. J. Org. Chem. 1979, 44, 3524-3529. https://doi.org/10.1021/jo01334a017

74 Spyroudis, S.; Varvoglis, A. Synthesis 1976, 837-838.

https://doi.org/10.1055/s-1976-24231

75 De, S. K.; Mallik, A. K. Tetrahedron Lett. 1998, 39, 2389-2390.

https://doi.org/10.1016/S0040-4039(98)00205-6

76 Aggarwal, R.; Sumran, G.; Saini, A.; Singh, S. P. Tetrahedron Lett. 2006, 47, 4969-4971. https://doi.org/10.1016/j.tetlet.2006.04.086

77 Raihan, M. J.; Kavala, V.; Habib, P. M.; Guan, Q.-Z.; Kuo, C.-W.; Yao, C.-F. J. Org. Chem. 2011, 76, 424-434. https://doi.org/10.1016/j.tetlet.2006.04.086

78 Kotali, A.; Lafazanis, I. S.; Harris, P. A. Molbank 2008, M572.

https://doi.org/10.3390/M572

79 Kotali, A. Molbank 2008, M573. https://doi.org/10.3390/M573

80 Kociolek, M. G.; Hoermann, O. Synth. Commun. 2012, 42, 2632-2638. https://doi.org/10.1080/00397911.2011.563451

81 Boulton, A. J.; Tsoungas, P. G.; Tsiamis, C. J. Chem. Soc., Perkin Trans. 1 1986, 1665-1667. https://doi.org/10.1039/p19860001665

82 Wang, K.; Fu, X.; Liu, J.; Liang, Y.; Dong, D. Org. Lett. 2009, 11, 1015-1018. https://doi.org/10.1021/ol802952e

83 Jen, T.; Mendelsohn, B. A.; Ciufolini, M. A. J. Org. Chem. 2011, 76, 728-731. https://doi.org/10.1021/jo102241s

84 Kita, Y.; Dohi, T. Chem. Rec. 2015, 15, 886-906. https://doi.org/10.1002/tcr.201500020

85 Uyanik, M.; Ishihara, K. Chem. Commun. 2009, 2086-2099. https://doi.org/10.1039/b823399c 
86 Ochiai, M.; Miyamoto, K. Eur. J. Org. Chem. 2008, 4229-4239.

https://doi.org/10.1002/ejoc.200800416

87 Han, L.; Zhang, B.; Xiang, C.; Yan, J. Synthesis 2014, 46, 503-509.

88 Xiang, C.; Li, T.; Yan, J. Synth. Commun. 2014, 44, 682-688.

https://doi.org/10.1080/00397911.2013.834364

\section{Authors Biographies}

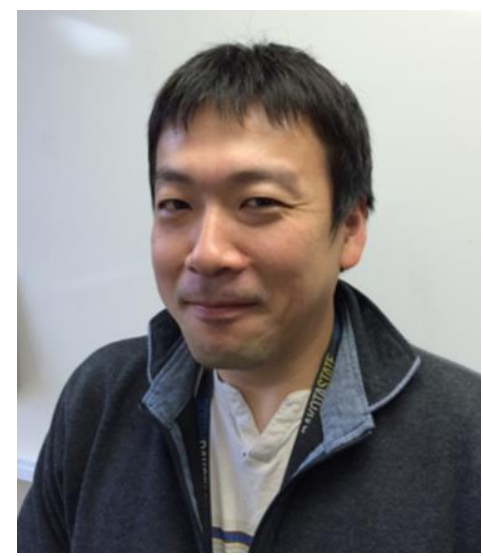

Akira Yoshimura, a native of Osaka, Japan, received his M.S. in 2007 and Ph.D. in 2010, both from Tokushima University, under the supervision of Professor Masahito Ochiai. During 2010-2014 he carried out postdoctoral work with Professor Viktor Zhdankin at the University of Minnesota Duluth, and in 2015 he was appointed to a Research Associate position in the same university. In 2016, he moved to the present position as a Visiting Research Assistant Professor in Southern Methodist University. His research interests are in the fields of synthetic and mechanistic organic chemistry of hypervalent main-group elements and heterocyclic chemistry. He has published over 40 research papers, mainly related to the chemistry of hypervalent iodine and bromine.

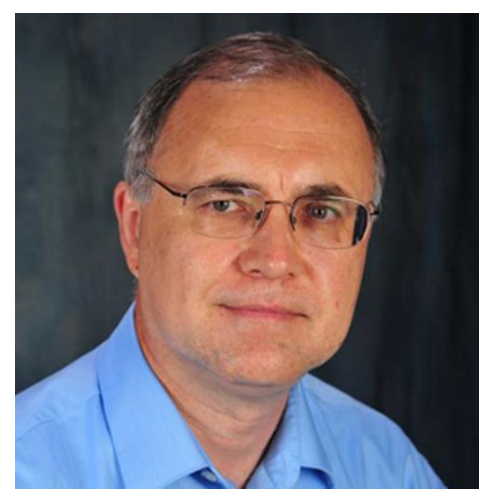

Viktor V. Zhdankin: was born in Ekaterinburg, Russian Federation. His M.S. (1978), Ph.D. (1981), and Doctor of Chemical Sciences (1986) degrees were earned at Moscow State University. He moved to the University of Utah in 1990, where he worked for three years as Instructor of organic chemistry and Senior Research Associate with Professor Peter J. Stang. In 1993, he joined the faculty of the University of Minnesota Duluth, where he is currently a Professor of Chemistry. Dr. Zhdankin has published over 250 research papers, given over a hundred research presentations in many countries, edited several books, co-authored the Handbook of 
Heterocyclic Chemistry (3rd Edition, 2010) with Professors A. R. Katritzky, C. A. Ramsden, and J. A. Joule, and authored a book on Hypervalent lodine Chemistry (Wiley, 2013). His main research interests are in the areas of synthetic and mechanistic organic chemistry of hypervalent main-group elements and organofluorine chemistry. In 2011 he received the National Award of the American Chemical Society for Creative Research \& Applications of lodine Chemistry. Since 2003 he is Scientific Editor and a Member of Control Board of Arkivoc. 